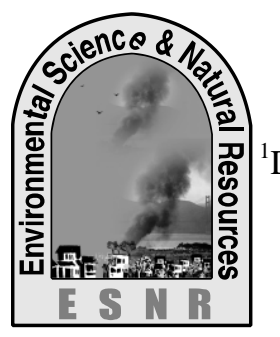

\section{Screening of Fruit Wastes as Pectin Source}

\section{R. Begum ${ }^{1 *}$, Y. A. Yusof ${ }^{1}$, M. G. Aziz ${ }^{2}$ and M. B. Uddin ${ }^{2}$}

Department of Food Technology and Nutritional Science, Faculty of Life Science, Mawlana Bhashani Science and Technology University, Santosh, Tangail-1902, Bangladesh,

${ }^{2}$ Department of Food Technology and Rural Industries, Bangladesh Agricultural University, Mymensingh 2202, Bangladesh

*Corresponding author: rokeya15@yahoo.cm

\begin{abstract}
This study was carried out on estimation of inedible part (waste) of fruit and screening for potential pectin content (calcium pectate) in fruit wastes with respect to type, location and maturity. Fruit waste generation was significantly different in different fruit type, variety and maturity. In a whole fruit, amount of fruit waste (peel \& core) was significantly higher than amount of fruit pulp. Among the waste evaluated the overall calcium pectate producing potential in order of merit were lemon, dragon fruit, guava, mango, jackfruit, banana, pomegranate, papaya, watermelon and pineapple. Unused fruit waste could be potential sources of pectin production.
\end{abstract}

Key words: Calcium pectate, Inedible part of fruit, Maturity, Screening and Variety

\section{Introduction}

Bangladesh is mainly an agricultural country. Agriculture plays a dominant role in its economy in terms of sustainable land management, food security, value addition, employment and export earnings. Total cultivable area is 8.5 million hector (BBS, 2013). The climate (both tropical and sub-tropical) and the soil of Bangladesh are suitable for fruits and vegetables production. Annual fruit production is 4.52 million tons from 0.24 million hector of land (BBS, 2013). The major fruits are namely various kinds of citrus fruit, jackfruit, mango, pine-apple, papaya, guava, banana, melon, water melon, litchi, ber, hog plum etc, which are grown in different season and different parts of the country. Besides the fresh consumption, these fruits are processed into variety of products such as juice, juice concentrate, pulp, canned and dehydrated products, jam, jellies, pickles, chutney etc. Around $1 \%$ fruits are processed to value added products. During commercial processing as well as house consumption of these fruits, a large quantity of waste such as; mango 35-60\% (Larrauri et al., 1996), jackfruit 60\% (Subburamu et al., 1992), papaya 50\% (Yang et al., 1984) banana 30\% (Wadhwa et al., 2014), pineapple 54\% (Mohamed and Hasan, 1995) orange 30-50 of total weight of fruit produced in the form of peel, pomece and seed which are thrown to the environment. Now a days food processing industry in Bangladesh is a rapidly growing sector. Between 2004 and 2010, the food processing industry in Bangladesh grew at an average 7.7 percent per annum (Food industries in Bangladesh, Wikipedia). By reason of the high consumption and industrial processing of the edible parts of these fruits, byproducts (mainly peels, pomace and seeds) are generated in large quantities. Fruit wastes are highly perishable, which is a great problem to the processing industries and the pollution monitoring agencies. Currently two main techniques are used to dispose these wastes, such as landfill and incineration. Nonetheless, inappropriate management of landfill will result in emissions of methane and carbon dioxide (Qdais et al., 2010), and incineration comprises the ensuing formation and releases of pollutants and secondary wastes such as dioxins, furans, acid gases as well as particulates (Buekens and Huang, 1998), which pose serious environmental and health risks. Animal feed is another use of fruit waste which is expensive as fruit waste contain high moisture. For these reasons, value added use for fruit waste is crucial. It is awaited that the discarded waste materials could be utilized for further industrial purposes viz. fermentation, extraction of bioactive components, extraction of functional ingredients etc and making them full use in the food, pharmaceutical as well as cosmetics industry (Makris et al., 2007).

Pectin is a secondary ingredient, widely used in food industry as gelling, thickening and emulsifying agent to manufacturing jam, jellies, preservatives, sauce, dairy products etc. Besides, it finds numerous applications in pharmaceutical preparations, pastes, cosmetics etc. The developing country like Bangladesh has to import this secondary ingredient at high price which affect the cost of the product enormously. It is interesting that this biopolymer can be found abundantly in fruit pulp, core and skin which are mostly discarded during processing. The amount of pectin content in fruits varies with type, variety, maturity and even the part of fruit (Nelson et al., 1977). It is a good idea to identify the important source of this valuable by product by determining the pectin content of fruit waste. For that reason the current research stand on the screening of fruit as a source of pectin.

\section{Materials and Methods}

This research work was carried out during June 2013 to March 2015 in the Department of Food Technology and Rural Industries, BAU, Mymensingh, Bangladesh and the Department of Process and Food Engineering, UPM, Malaysia.

\section{Materials}

Around 30 samples were selected to check the waste content and calcium pectate content of each fruit based on season, fruit maturity, fruit variety and location of fruit from Bangladesh and Malaysia. Samples were bought from local market and the germ plasm Centre, BAU, Mymensingh. Chemicals such as hydrochloric acid $(37 \%)$, sodium hydroxide (AR), acetic acid 
(99.5\%), calcium chloride (2 hydrate AR) and silver nitrate (AR) were purchased from $R$ \& $M$ marketing.

\section{Percent fruit waste calculation}

Fruits were physically examined to ascertain their wholesomeness, washed and all adhere water were removed. The peel, core, seed and pulp/bulb were separated from each other and weighed separately to calculate percent waste and stored at $-30^{\circ} \mathrm{C}$ for further analysis.

\section{Estimation of pectin as calcium pectate}

Pectin content in different types, variety and parts of different fruits was determined as calcium pectate using the gravimetric method described by Rangana (1986). The $50 \mathrm{~g}$ blended samples were extracted with $400 \mathrm{ml}$ $0.05 \mathrm{~N}$ hydrochloric acid $(\mathrm{HCl})$ for 2 hours at $85^{\circ} \mathrm{C}$. Then volumes were made up to $500 \mathrm{ml}$ with distilled water and were filtered through No. 4 What man filter paper. Then $100 \mathrm{ml}$ aliquots was diluted $250 \mathrm{ml}$ distilled water and the acid was neutralized with $1 \mathrm{~N}$ sodium hydroxide. Then $10 \mathrm{ml}$ of $1 \mathrm{~N}$ sodium hydroxide was added in excess and allowed to stand overnight. Exactly $50 \mathrm{ml}$ of $1 \mathrm{~N}$ acetic acid was added and after 5 minutes $25 \mathrm{ml}$ of $1 \mathrm{~N}$ calcium chloride was added with continuous stirring. The solution was allowed to stand for 1 hour, and then boiled for 1-2 minutes. Then the solution was filtered through previously prepared (wet the filter paper in hot water, dried in oven at $102^{\circ} \mathrm{C}$ for 2 hours, cooled in a desiccator and weighed in a covered dish washed with hot water and dried at $102{ }^{\circ} \mathrm{C}$ for 2 hours) filter paper. The residue remained on the filter paper was washed thoroughly with almost boiling water to free from chloride. Silver nitrate was used to test the presence of chloride. Filter paper containing calcium pectate was transferred to weighing dish, dried in an oven at $100^{\circ} \mathrm{C}$ to constant weight, cooled in a desiccator and weighed along with the filter paper.

The pectin content was calculated and expressed as per cent calcium pectate using the equation below:

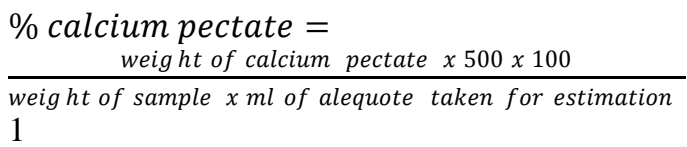

\section{Results and Discussion}

This study was carried out on screening of fruit waste for potential pectin content (calcium pectate) with respect to type, location and maturity.

\section{Fruit waste estimation}

Fig. 1 to 4 present the fruit wastes/byproducts discarded as peel, core, seed and press during consumption and processing.

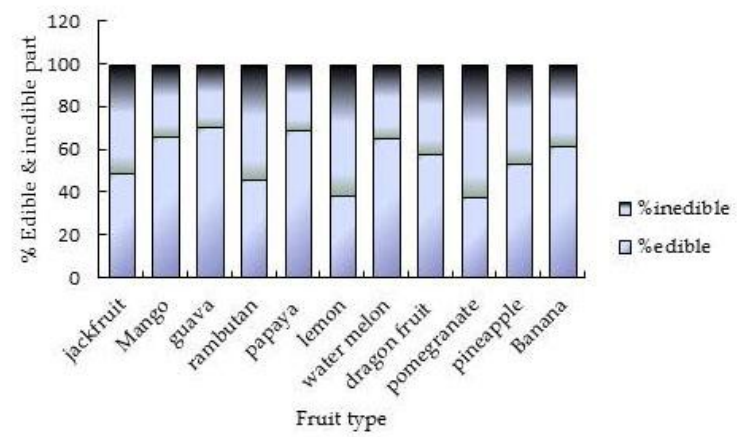

Fig. 1. Edible and inedible part of selected fruit waste.

Fig.1 presents overall edible and inedible part of a fruit. Initially 11 samples were analyzed for estimating waste. Experiments revealed that the amount of edible portion of whole fruit is significantly different from inedible portion. Among the fruit analyzed water melon, guava, banana, mango and papaya contained more than $60 \%$ edible biomass. Dragon fruit and pineapple had more than $50 \%$ edible biomass. On the contrary jackfruit, rambutan, pomegranate and lemon contained significantly higher amount of inedible biomass. Besides, production of waste from fruit varied with types of fruit, their variety and ripening condition. Fig. 2 and 3 showed that wastes generated from different variety of lemon and guava were also different. Guava from Malaysia generated less amount of waste than that of from Bangladesh (Fig. 2).

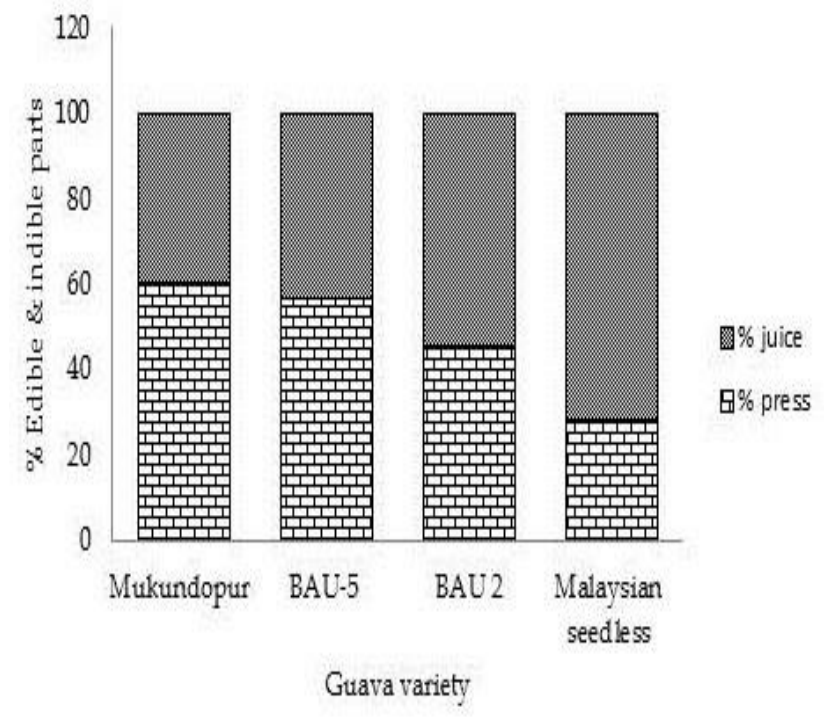

Fig. 2. Effect of guava variety on edible and inedible part.

Among lemons collected both from Bangladesh and Malaysia, the highest $(73 \%)$ waste was obtained from Eureka lemon and the lowest (40\%) from BAU5 (Fig. 3) 


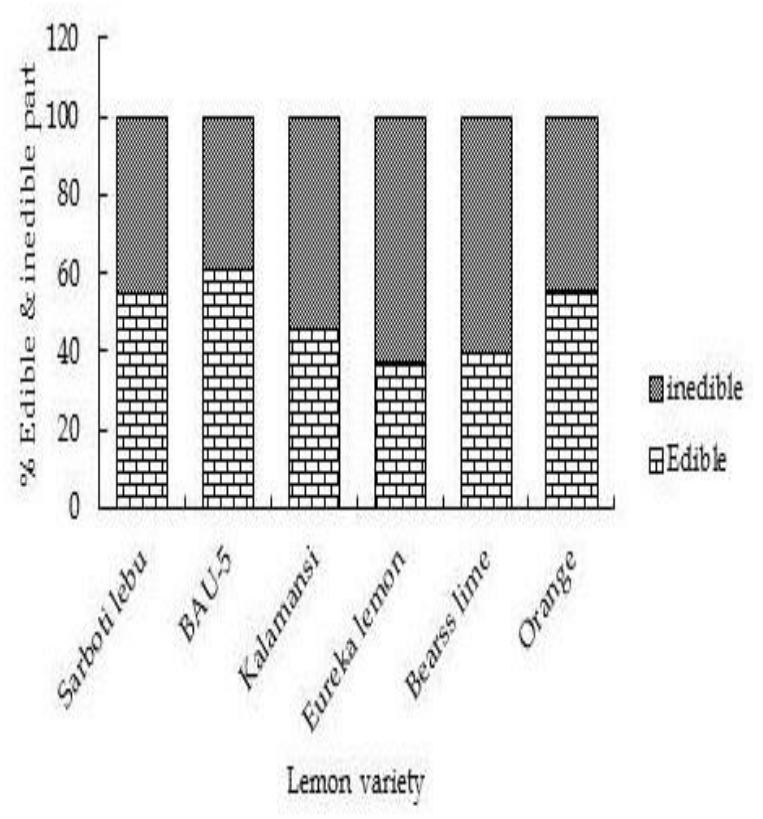

Fig. 3. Effect of lemon variety on edible and inedible part

The composition of the flesh, seed and rind also varied considerably with maturity of fruit (Fig. 4). Green papaya and mango generated higher quantity of edible biomass (flesh) and reduced the inedible portion (skin and seed). Ripeness increased $15 \%$ to $63 \%$ inedible biomass for mango and papaya. These results are consistent with findings of earlier researchers. Previous results revealed that mango $(40 \%)$, pineapple $(45 \%)$, guava $(30 \%)$, jackfruit $(59.2 \%)$, water melon $(32 \%)$, papaya $(50 \%)$ produce abundance of waste from fruit processing (Yang et al., 1984; Subburamu et al., 1992; Mohamed and Hasan, 1995; Campbell, 2006; Yatnatti et al., 2014). The major wastes of mango processing are peel and seeds, amounting $40 \%$ of the total fruit weight (Yatnatti et al., 2014). Pineapple canning industries produces around $45 \%$ of the total weight as waste and discarded (Mohamed and Hasan, 1995). Banana peels constitute up to $30 \%$ of the ripe fruit (Mohamed and Hasan, 1995). Watermelon in three main components which are the flesh, seed, and rind, the flesh constitutes approximately $68 \%$ of the total weight whereas the remaining portion $(32 \%)$ is rind and seeds (Cambell, 2006). Guava cake (peel, pulp and seeds) is a byproduct from juice production, accounts for $30 \%$ of guava fruit weight and is commonly used as animal feed or fertilizer. Yang et al. (1984) reported that the processing of papaya resulted in more than $50 \%$ of total weight as waste. The amount of residue obtained from citrus fruits accounts for $50 \%$ of the original mass of the whole fruit (Chon et al., 1997). Jackfruit consumption produce $59.1 \%$ of the fruit as waste (rind, core and undeveloped parianth) (Subburamu et al. 1992) while in the canning of jackfruit the rejected part is $80-85 \%$ in the total fruit (Muhammad, 1972).

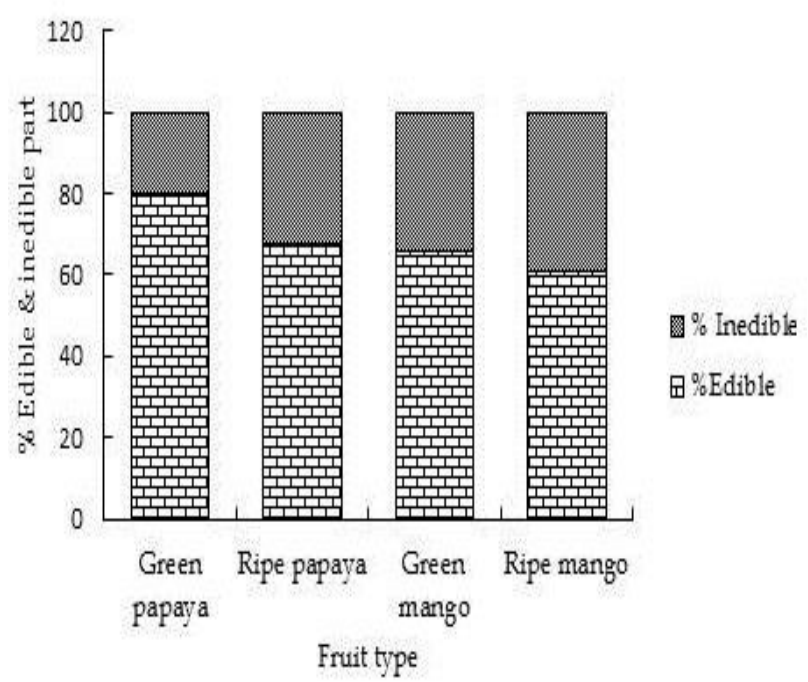

Fig. 4. Effect of ripening on edible and edible part of fruit

\section{Screening of fruit waste as a source of pectin}

Twenty fruit samples were selected from Bangladesh and Malaysia and analyzed to determine their pectin content as calcium pectate to find the potential pectin containing fruit waste. Fig. 5 and 6 present the calcium pectate content (dry basis) of eight different fruit peels and fruit waste (inedible portion) respectively.

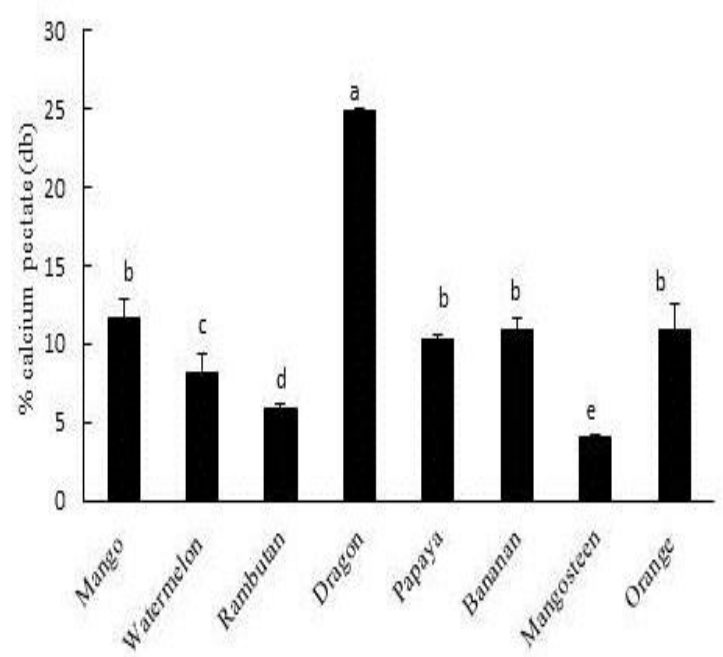

Fig. 5. Calcium pectate content of different fruit peel. Mean value from two replicates were used to draw bar chart with error bar. Bars with different superscript are significantly different $(\mathrm{p}<0.05)$

Fig. 4 revealed that calcium pectate content varied significantly from fruit to fruit. Dragon fruit contained the highest $(24.83 \%)$ and mangosteen peel the lowest $(4.03 \%)$ whereas mango, banana, papaya, orange peel contained moderate $(10.29-11.63 \%)$ calcium pectate. Among the fruit wastes pineapple contained the lowest $(5.03 \%)$ and guava press the highest $(13.03 \%)$ and followed by jackfruit $(11.43 \%)$ and pomegranate $(10.45 \%)$ waste as far as concerned to the content of calcium pectate (Fig. 6). The amount of pectin determined as calcium pectate was not static always, 
which is in agreement with previous findings (Nelson et al., 1977).

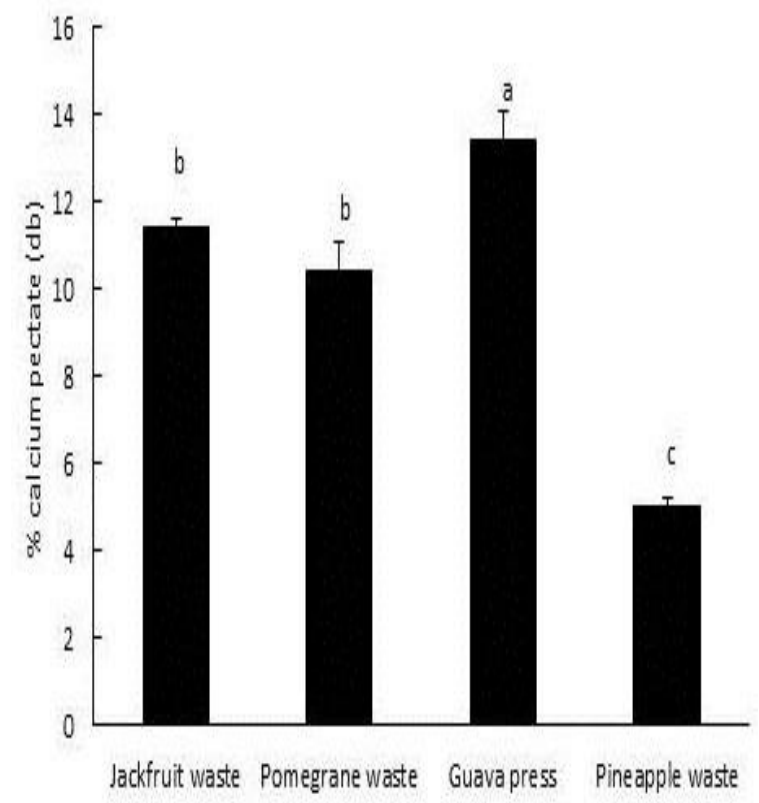

Fig. 6. Calcium pectate content of different fruit waste. Mean value from two replicates were used to draw bar chart with error bar. Bars with different superscript are significantly different $(\mathrm{p}<0.05)$.

Fruit variety also effects on the calcium pectate content. Seedless guava contained the highest amount of calcium pectate $(13.43 \%)$ among the guava samples analyzed (Fig. 7). Similarly bearss lime peel contained significantly higher $(32.3 \%)$ calcium pectate among the lemon peels analyzed (Fig. 8).

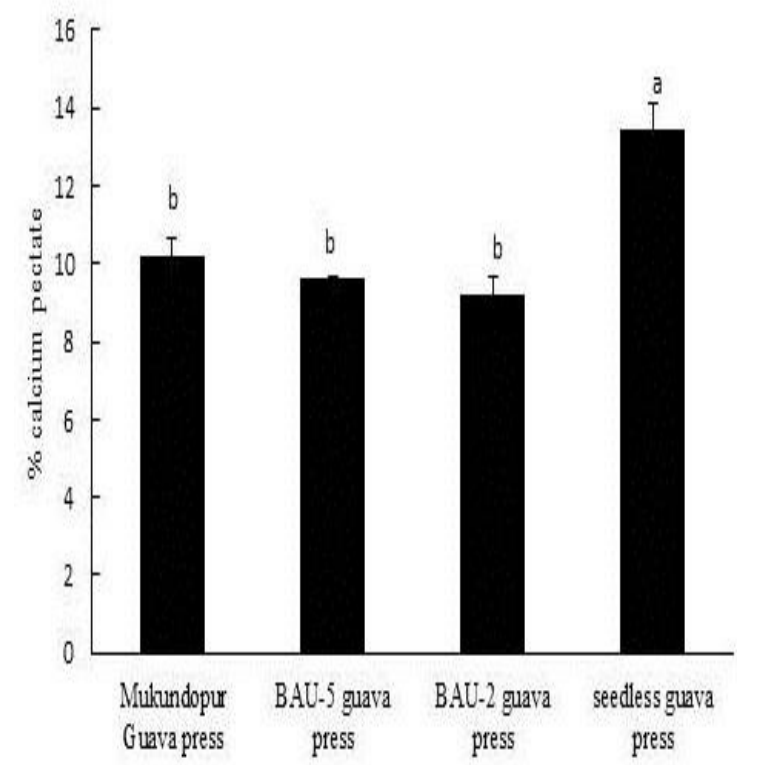

Fig. 7. Effect of guava variety on calcium pectate content. Mean value from two replicates were used to draw bar chart with error bar. Bars with different superscript are significantly different $(\mathrm{p}<0.05)$.

Calcium pectate content was affected by the fruit maturity (Fig. 9). Ripening reduced calcium pectate content significantly in the mango and the papaya peel. During ripening pectin contents reduced $31.17 \%$ and $35.64 \%$ from papaya and mango peel, respectively. Highest calcium pectate was found in the peel and core and the lowest in the bulb or edible portion (Fig. 10).

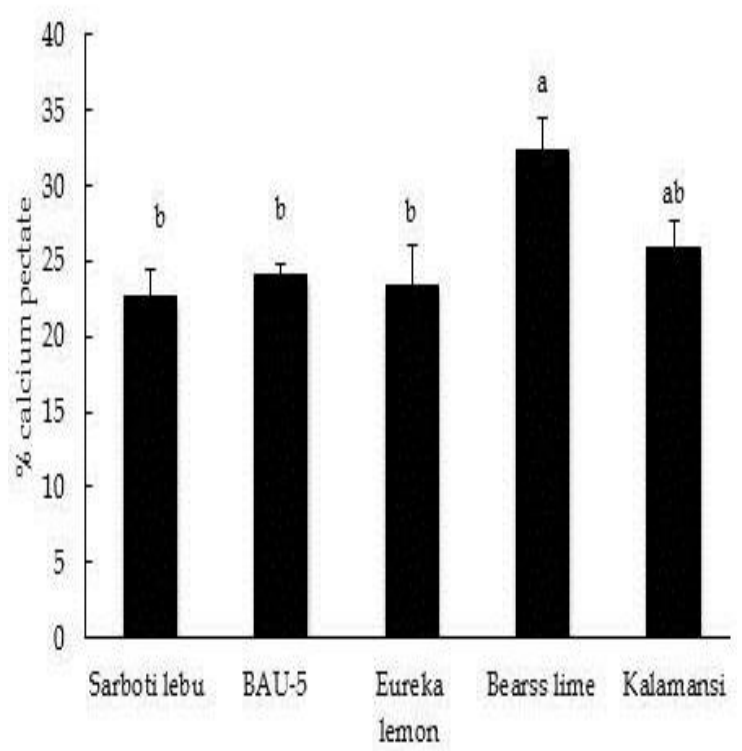

Fig. 8. Effect of guava variety on calcium pectate content.Mean value from two replicates were used to draw bar chart with error bar. Bars with different superscript are significantly different $(\mathrm{p}<0.05)$.

Pectin content in the same fruit not only varies with variety but also with location within a fruit and it's ripening condition. Reason behind may be the contribution of pectin to the firmness and structure of plant tissue both as a part of the primary cell wall and as the main middle lamella component involved in intercellular adhesion similar to the intercellular substance of animal origin (collagen) (Glickman, 1969)

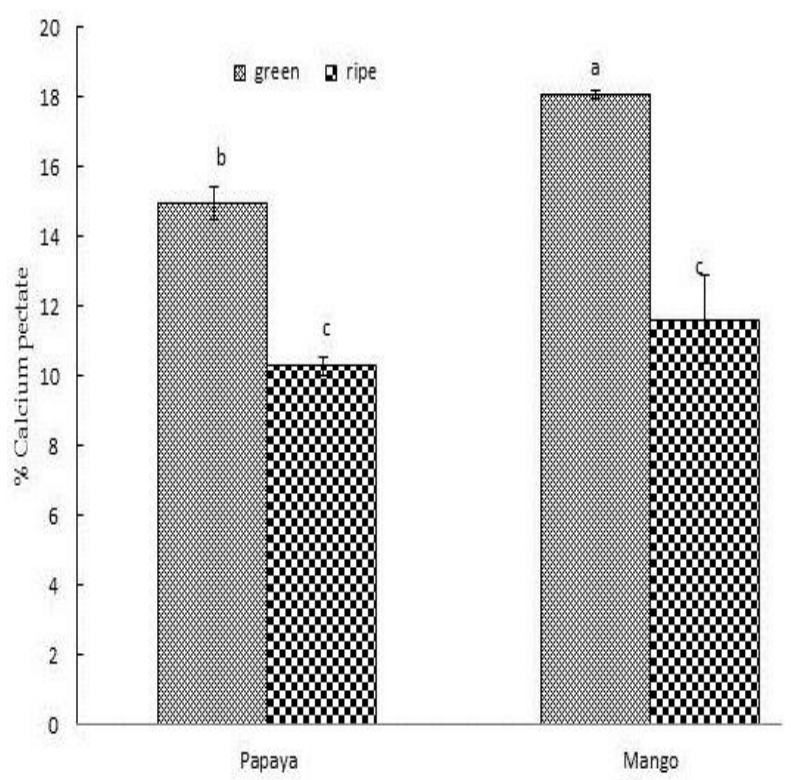

Fig. 9. Effect of fruit maturity on calcium pectate content. Mean value from triplicate replicate were used to draw bar chart with error bar. Bars with different superscript are significantly different $(\mathrm{p}<0.05)$. 
The strength of the plant cell wall depends on the orientation, mechanical properties, and links between pectic substances and cellulose fiber (Preston, 1979). Glickman (1969) reported that pectin is present in various stages of molecular development and transformation that are dependent on the specific morphology and taxonomy of the plants as well as the stage of growth and maturity. On the other hand, during ripening ezymetic degradation and solubilization of protopectin cause softening of fruit (Mollendroff et al., 1993). The general concept is that textural changes occur as cell wall pectin is hydrolyzed by polygalacturonases consequence reduction in pectin content.

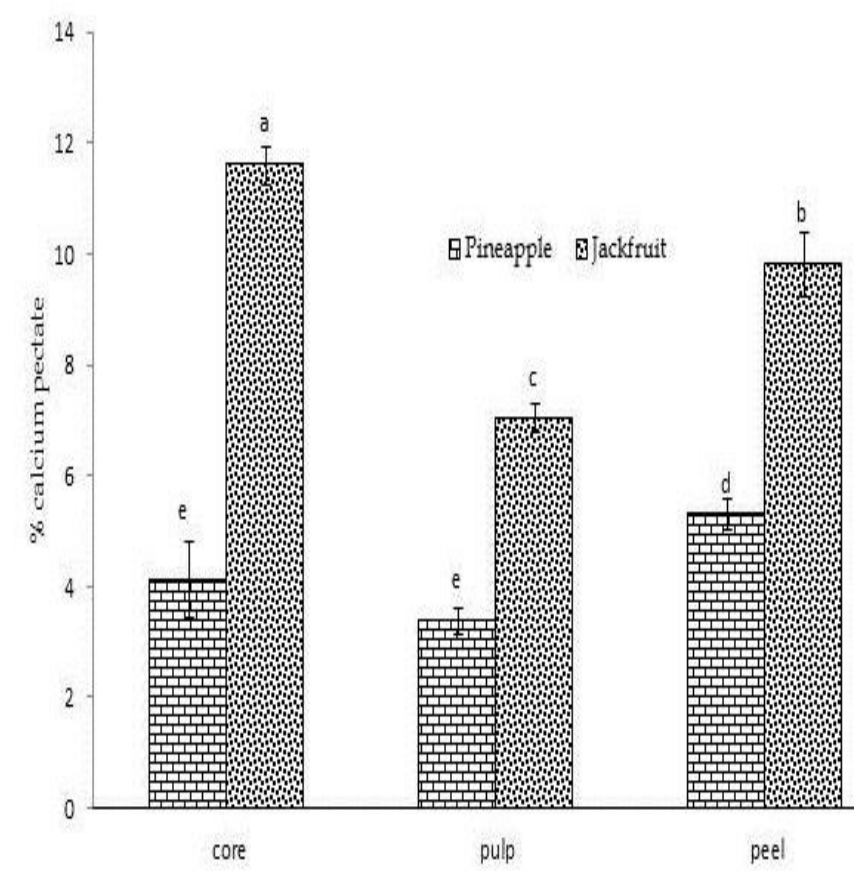

Fig. 10. Effect of fruit location on calcium pectate content. Mean value from triplicate replicate were used to draw bar chart with error bar. Bars with different superscript are significantly different $(\mathrm{p}<0.05)$.

\section{Conclusion}

Pectin is an important food ingredients used in manufacturing different food products. Commercial food grade pectin is manufactured from apple and orange peels. In this work a comprehensive study has been carried to assess potentiality of tropical fruit wastes as a source of pectin. Among the wide range of tropical fruit wastes screened for pectin content, dragon fruit, lime, guava, mango and jackfruit were found as potential sources for pectin production. However, these selections also depend on availability and the volume of waste generated.

\section{Acknowledgements}

The authors would like to acknowledge Ministry of Education, Bangladesh and Organization for Women in Science for the Developing World (OWSD) for their financial support and the Ministry of Education Malaysia for granting the Fundamental Research Grant
Scheme (FRGS) with the project code: 03-02-131289FR.

\section{References}

Bangladesh Bureau of Statistics. 2013. Yearbook of Agriculture Statistics, 2012-2013.

Buekens, A. and Huang. H. 1998. Comparative evaluation of techniques for controlling the formation and emission of chlorinated dioxins/ furans in municipal waste incineration. Journal of Hazard Mater, 62: 1-33.

Cambell, M. 2006. Extraction of pectin from watermelon rind, Bachelor of Science. Thesis, Department of Biosystems Engineering, Oklahoma State University, America.

Chon, R. and Chon, A. L. 1997. Sub productos del procesado de las frutas. In: PR Ashurst (Editor), Procesado de frutas. Acribia, Zaragoza. pp. 213228.

Food industries in Bangladesh, https://en.wikipedia.org/wiki/ food_industry_inBangladesh.

Glickman, M. 1969. Gum Technology in the Food Industry, Academic Press, New York.

Larrauri, J. A.; Rupérez, P.; Borroto, B. and SauraCalixto, F. 1996. Mango peels as a new tropical fibre: Preparation and characterization. Lebensmittel-WissenschaftUnd-Technologie, 29(8): 729-733, ISSN 0023-6438

Makris, D. P.; Boskou, G.; and Andrikopoulos, N. K. 2007. Recovery of antioxidant phenolics from white vinification solid by-products employing water/ethanol mixtures. Bioresour Technol, 98: 2963-2967.

Mohamed, S. and Hasan, Z. 1995. Extraction and characterisation of pectin from various tropical agrowastes. ASEAN Food Journal, 10: 143-150.

Mollendroff, L. J.; Von Villiers, O. T.; de Jacobs, G. and Westraad, I.1993. Molecular characteristics of pectin constituents in relation to firmness, extractable juice, and woolliness in nectarines. Journal of American Society for Horticultural Science, 118: 77.

Muhammad, Y. 1972. Some Major Factors Worth Consideration in Manning for a Diversified Fruit Processing Plant, Ministry of Agriculture and Fisheries, K. L., Malaysia.

Nelson, D. B.; Smit, J. C. B. and Wiles, R. R. 1977. Food Colloids, ed. H. D. Graham, the AVI Publishing Company.

Preston, R. D. 1979. Polysaccharide: conformation and cell wall function. Rev. Plant Physiol., 30: 55.

Qdais, H. A.; Abdulla, F. and Qrenawi, L. 2010. Solid waste landfills as a source of green energy: Case study of Al Akeeder landfill. Jordan J. Mech. Ind. Eng., 4: 69-74.

Ranganna S. 1986. Manual of Analysis of Fruits and Vegetable Products.Tata McGraw Hill publishing Company Ltd. New Delhi, pp. 40-42.

Subburamu K.; Singaravelu,A; Nazar and Irulappan, I. 1992. Short Communication, 40: 85-86. 
Wadhwa, M.; Bakshi, M. P. S. and Makkar, P. S. 2013. Utilization of fruit and vegetable wastes as livestock feed and as substrates for generation of other value-added products. RAP Publication, FAO.
Yang, P. Y.; Weitzenhoff, M. M. and Moy, J. H. 1984. Biogasification of the papaya processing wastes. Transactions of the ASAE, 27(3): 840-843.

Yatnatti, S.; Vijayalakshmi, D. and Chandru, R. 2014. Processing and Nutritive Value of Mango Seed Kernel Flour. Centre Research in Nutrition and Food Science, 2(3): 170-175. 